Nigerian Journal of Technology (NIJOTECH)

Vol. 38, No. 1, January 2019, pp. $104-111$

Copyright@ Faculty of Engineering, University of Nigeria, Nsukka,

Print ISSN: 0331-8443, Electronic ISSN: 2467-8821

www.nijotech.com

http://dx.doi.org/10.4314/njt.v38i1.14

\title{
OPTIMISATION OF ACETYLATION PARAMETERS FOR REDUCED MOISTURE ABSORPTION OF BAMBOO FIBRE USING TAGUCHI EXPERIMENTAL DESIGN AND GENETIC ALGORITHM OPTIMISATION TOOLS
}

\author{
O. S. Onyekwere ${ }^{1, *}$, A. C. Igboanugo ${ }^{2}$ and T. B. Adeleke ${ }^{3}$ \\ 1, FACULTY OF Engineering, Federal UniVersity WUKARI, WUKARI, TARABA STATE, NIGERIA

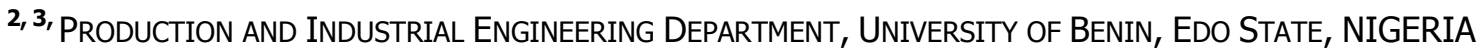 \\ E-mail addresses: ${ }^{1}$ smithonyekwere@gmail.com; ${ }^{2}$ anthonyigboanugo@uniben.edu, ${ }^{3}$ tundebasit123@gmail.com
}

\begin{abstract}
Natural fibres have good weight-to-strength ratio which has made it a material of interest for scientists and engineers. However, the major drawback for outdoor application of natural fibres is its hydrophilic nature. In this study, attempt was made to render bamboo fibre hydrophobic through acetylation with acetic anhydride at room temperature. The functional water absorption properties were studied and the acetylation parameters, such as chemical dosage and acetylation time, were optimised. Taguchi Orthogonal Array was used for the experimental design. Based on the Taguchi design, a regression equation was generated which served as an objective function for Genetic Algorithm. Acetylation reduced the percentage water absorption of Bambusa Vulgaris fibre from $196.4 \%$ in un-acetylated fibre down to $45 \%$ in acetylated fibres within the feasible design space. The optimal parameter setting generated with genetic algorithm is $15 \%$ acetic acid concentration, 50minutes of time soaked in acetic acid, 5\% acetic anhydride concentration and 30 minutes time soaked in acetic anhydride. Under the optimum condition, the percentage water absorption was $44 \%$. A confirmation experiment validated the effectiveness of the Genetic Algorithm result.
\end{abstract}

Keywords: Acetylation, Bamboo Fibre, Taguchi, Optimisation, Genetic Algorithm

\section{INTRODUCTION}

The major limitation for outdoor engineering application of natural fibre is its high propensity to absorb moisture. In composite production, hydrophilic nature of plant fibres results in poor interfacial adhesion between polar-hydrophilic fibre and non-polar-hydrophobic matrix, difficult in mixing due to poor wetting of fibre with matrix which, in turn leads to composites with weak interface and dimension instability of the resulting product [1]. Therefore, there is need to reduce the percentage water absorption of natural fibres before incorporating them in composite production and other engineering applications.

Many processes have been developed for modification of natural fibres for reduced water absorption. However, one of the major drawbacks for industrial application of these modification processes is their high thermal energy requirement and high cost of chemicals $[2,3]$. Thus, there is need for indepth study of low energy modification processes.

The modification of fibres aims to enhance the interfacial adhesion between fibre and matrix and to alter the absorptive behaviour of fibre and thus gives an advantage in terms of dimensional stability and wetting of fibre [4-6]. Hence, modification process with low thermal energy and lesser chemical requirement will give rise to viable industrial production of hydrophobic or near hydrophobic natural fibres which would be suitable for outdoor engineering applications.

Many chemical modification methods have been employed to improve the performance of natural fibre composites [7]. Among all chemical modifications, acetylation is one of the most accepted approaches in the production of biopolymer

* Corresponding author, tel: +234-803-390-6099 
composites because; it is relatively inexpensive and eco-friendly. The main principle of acetylation is to substitute the hydroxyl groups $(\mathrm{OH})$ of natural fibre with acetyl groups $\left(\mathrm{CH}_{3} \mathrm{CO}\right)$ thereby rending the fibre surface more hydrophobic. However, acetylation is usually done at high temperature in the presence of a catalyst. The cost of the resulting product reflects the high cost of production.

Hassan et al, [8] reported on chemical modification of oil palm fruit bunch hybrid composite noting that during acetylation, the mixture of acetic acid and acetic anhydride was warmed gently to $45^{\circ} \mathrm{C}$ for one hour after which $0.65 \mathrm{~cm}^{3}$ of concentrated $\mathrm{H}_{2} \mathrm{SO}_{4}$ was added as a catalyst. In a research on acetylation of rice straw, Kai et al [7], mixed $80 \mathrm{~g}$ of acetic acid and $20 \mathrm{~g}$ of rice straw at $40^{\circ} \mathrm{C}$ for 3 hours after which $60 \mathrm{~g}$ of acetic anhydride and $1.8 \mathrm{~g}$ of sulphuric acid were added to the mixture and allowed to react for 2 hours at $50^{\circ} \mathrm{C}$. It is noteworthy that the aforementioned researchers applied high temperature and catalyst in their acetylation process. Other researchers have also applied similar process in acetylation $[7,9,10]$. One of the drawbacks of application of catalyst and high temperature during acetylation is the non-commercial viability of the process because of high cost of chemicals and energy requirement. The aforementioned authors did not report the effect of acetylation on the functional percentage water absorption of the natural fibres without the influence of matrix.

Thus, this study was undertaken to employ a noncatalyzed room temperature liquid phase acetylation process in order to achieve a modification of large batches of bamboo fibre to facilitate industrial processing. The study was also carried out to investigate the effect of acetylation on bamboo fibre without the influence of matrix materials and the optimum factor setting for "room temperature" acetylation. Taguchi orthogonal array and genetic algorithm was employed for the design and optimisation of acetylation parameter settings.

\section{MATERIALS AND METHOD}

\subsection{Materials}

Bamboo fibres were obtained from Camic chemical shop, Aba Nigeria. Acetic Acid and Acetic anhydride used for acetylation was obtained from local chemical shop in Aba, Nigeria. Figure 1 shows the bamboo fibres used for the acetylation studies.

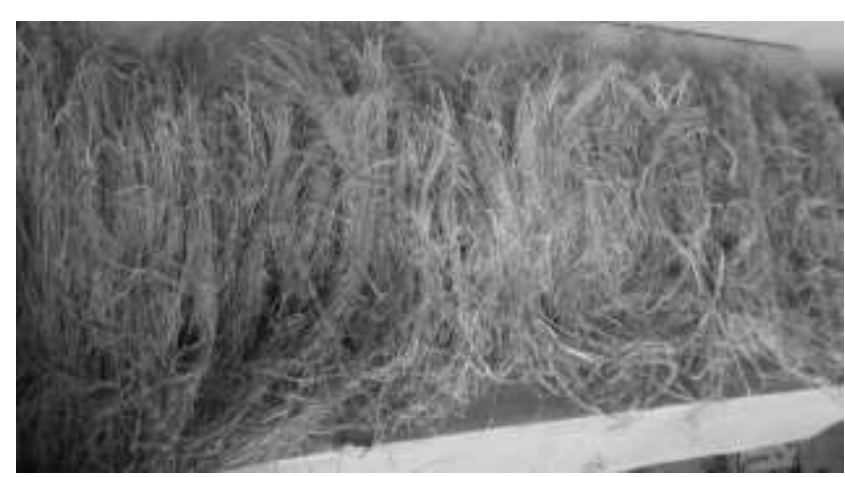

Figure 1: Bamboo fibres used for acetylation

\subsection{Experimental Design}

The optimization steps applied in this study is as follows.

- Select control factors

- Select Taguchi orthogonal array

- Conduct Experiments

- Measure the response

- Generate regression equation from Taguchi design experimental response

- Use the regression equation as objective function for Genetic algorithm

- Conduct Genetic Algorithm optimisation

Traditional experimental designs usually involve a large number of experimental works as the number of process parameters increases. On the other hand, the Taguchi method uses a special design of orthogonal arrays to study the entire parameter space with only a small number of experiments. A Taguchi technique is a design of experiment approach (DOE) which attempts to extract maximum important information with minimum number of experiments. It uses standard Orthogonal Arrays (OA) for forming a matrix of experiments. The use of $\mathrm{OA}$ to design experiment helps to study the influence of multiple controllable factors on the average of quality characteristics and the variations in a fast and economic way $[11,12]$.

\subsubsection{Control Factors Selection}

During acetylation process, acetic anhydride does the actual substitution of hydroxyl groups, in fibre, with acetyl groups while acetic acid causes swelling of the fibres for easy penetration of acetic anhydride. However, decrease in strength with soaking time of fibre in acetic acid has been reported [13]. Previous researchers used different concentrations and soaking time of reagent for acetylation [13 - 16]. Thus, there is no agreement on the acetylation 
parameter setting for optimum water absorption properties.

In the present study, the level of control factors were selected from the range of parameter settings used by previous researchers and optimized to achieve the best setting within the feasible design space. Four operating parameters, each at three levels, are selected to evaluate the effect of acetylation on percentage water absorption of bamboo fibres. The factors are contained in Table 1.

\subsubsection{Taguchi Orthogonal Array}

Based on Taguchi method, the L27-OA was constructed. The Taguchi design of experiment was done using Minitab 17.0 software. The design matrix of the experiment, and the corresponding responses, is presented on Table 2 .

Table 1 Factors and their level in the experimental design

\begin{tabular}{ccccc}
\hline \multirow{2}{*}{ Level } & \multicolumn{4}{c}{ FACTORS } \\
\cline { 2 - 5 } & $\begin{array}{c}\text { Acetic Acid } \\
\text { Concentration (\%) }\end{array}$ & $\begin{array}{c}\text { Time Soaked in Acetic } \\
\text { Acid (Minute) }\end{array}$ & $\begin{array}{c}\text { Acetic Anhydride } \\
\text { Concentration (\%) }\end{array}$ & $\begin{array}{c}\text { Time Soaked in Acetic } \\
\text { Anhydride (Minutes) }\end{array}$ \\
\hline 1 & 5 & 10 & 5 & 30 \\
2 & 10 & 30 & 10 & 60 \\
3 & 15 & 50 & 15 & 90 \\
\hline
\end{tabular}

Table 2 Design matrix for acetylation of bamboo fibre

\begin{tabular}{lccccccc}
\hline Run & $\begin{array}{c}\text { Acetic Acid } \\
\text { Concentratio } \\
n\end{array}$ & $\begin{array}{c}\text { Time in Acetic } \\
\text { Acid }\end{array}$ & $\begin{array}{c}\text { Acetic Anhydride } \\
\text { Concentration }\end{array}$ & $\begin{array}{c}\text { Time in Acetic } \\
\text { Anhydride }\end{array}$ & $\begin{array}{c}\text { Percentage } \\
\text { Water } \\
\text { Absorption } \\
(\text { (hour) }\end{array}$ & $\begin{array}{c}\text { Percentage Water } \\
\text { Absorption (24 } \\
\text { hours) }\end{array}$ & $\begin{array}{c}\text { Difference in } \\
\text { Percentage water } \\
\text { Absorption } \\
\text { hours })\end{array}$ \\
\hline R1 & 5 & 10 & 5 & 30 & 60.46 & 111.34 & 84.8 \\
R2 & 5 & 10 & 10 & 60 & 47.42 & 89.44 & 106.7 \\
R3 & 5 & 10 & 15 & 90 & 37 & 89 & 107.14 \\
R4 & 5 & 30 & 5 & 30 & 44 & 67 & 129.14 \\
R5 & 5 & 30 & 10 & 60 & 50.2 & 109.28 & 86.86 \\
R6 & 5 & 30 & 15 & 90 & 63.84 & 110.46 & 85.68 \\
R7 & 5 & 50 & 5 & 30 & 42.92 & 77.72 & 118.42 \\
R8 & 5 & 50 & 10 & 60 & 62.76 & 105.64 & 90.5 \\
R9 & 5 & 50 & 15 & 90 & 57.1 & 88.34 & 107.8 \\
R10 & 10 & 10 & 5 & 60 & 52.48 & 83.34 & 112.8 \\
R11 & 10 & 10 & 10 & 90 & 57.78 & 104.88 & 91.26 \\
R12 & 10 & 10 & 15 & 30 & 59.44 & 104.92 & 91.22 \\
R13 & 10 & 30 & 5 & 60 & 69 & 127 & 69.14 \\
R14 & 10 & 30 & 10 & 90 & 50.04 & 84.84 & 111.3 \\
R15 & 10 & 30 & 15 & 30 & 38.9 & 81.56 & 114.58 \\
R16 & 10 & 50 & 5 & 60 & 48.48 & 60.62 & 135.52 \\
R17 & 10 & 50 & 10 & 90 & 35.82 & 57.98 & 138.16 \\
R18 & 10 & 50 & 15 & 30 & 54 & 98 & 98.14 \\
R19 & 15 & 10 & 5 & 90 & 69.6 & 108.62 & 87.52 \\
R20 & 15 & 10 & 10 & 30 & 54.26 & 81.86 & 114.28 \\
R21 & 15 & 10 & 15 & 60 & 68 & 110.34 & 85.8 \\
R22 & 15 & 30 & 5 & 90 & 45.02 & 90.66 & 105.48 \\
R23 & 15 & 30 & 10 & 30 & 49.46 & 77.22 & 118.92 \\
R24 & 15 & 30 & 15 & 60 & 51.28 & 82.54 & 113.6 \\
R25 & 15 & 50 & 5 & 90 & 58.54 & 96.34 & 99.8 \\
R26 & 15 & 50 & 10 & 30 & 31.34 & 45.02 & 151.12 \\
R27 & 15 & 50 & 15 & 60 & 56 & 80 & 116.14 \\
\hline
\end{tabular}




\subsubsection{Genetic Algorithm}

Genetic algorithms (GA) are stochastic algorithms in which the search method mimics some natural phenomena. The idea behind genetic algorithms is to do what nature does. Based on Darwin's survival of the fittest principles, the best and fittest design solutions, otherwise difficult to find, are found by GA's intelligent search procedure. The solution of an optimization problem with genetic algorithm begins with a set of potential solution or chromosomes. The chromosomes evolve during several iterations called generations. The new generations are generated utilizing the crossover and mutation technique. The chromosomes are then evaluated employing a certain fitness criteria and the best ones are kept while the other are rejected. This process repeats until the chromosomes have the best fitness and is taken as the optimal solution for the problem $[17,18]$.

In this research, a regression model was formulated from the experimental data. The developed model was then used as the objective function in Genetic Algorithm. The optimisation problem was formulated as follows,

Find: $X_{1}$ (Acetic Acid Concentration, \%), $X_{2}$ (Soaked Time in Acetic Acid, min.), $X_{3}$ (Acetic Anhydride Concentration, \%), $X_{4}$ (Soaked Time in Acetic Anhydride, $\mathrm{min})$.

Minimum: $Y\left(X_{1}, X_{2}, X_{3}, X_{4}\right)$,

Subjects to constraints: $X_{1} \min \leq X_{1} \leq X_{1} \max$.

$X_{2} \min \leq X_{2} \leq X_{2}$ max.

$x_{3} \min \leq x_{3} \leq x_{3} \max$.

$X_{4} \min \leq X_{4} \leq X_{4} \max$.

Where $Y=$ Percentage Water Absorption.

The objective function used for GA, which was developed using regression analysis, is shown in equation (1).

Objective Function $\mathrm{y}=116.33-3.63412 \mathrm{x}_{1}+$ $0.1033944 x_{2}+1.37982 x_{3}-0.567583 x_{4}-0.06255 x_{1} x_{2}$ $+0.0753067 x_{1} x_{4}$

MATLAB 8.0 GA Toolbox was used to develop the GA program. The GA, written in MATLAB programming language, selects chromosomes based on objective function and level of constraint violation. The default MATLAB genetic parameters were used in this research. The parameters are shown in Table 3.

\subsection{Acetylating of Fibres}

The main principle of acetylation method is to react the hydroxyl groups $(\mathrm{OH})$ of fibre with acetyl groups $(\mathrm{CH} 3 \mathrm{COO}-)$, thereby rendering the fibre surface more hydrophobic [19]. Non-catalyzed room temperature acetylation method was employed in this study. 10grams of fibres, from each run in Table 2 , were soaked in a beaker containing $200 \mathrm{ml}$ acetic acid (The acetic acid was prepared for different concentrations of $5 \%, 10 \%$ and $15 \%$ and soaking time of 10,30 and 50 minutes). The fibres were then transferred to a beaker containing $200 \mathrm{ml}$ acetic anhydride (the acetic anhydride was prepared for different concentrations of $5 \%, 10 \%$ and $15 \%$ for soaking time of 30,60 and 90 minutes). The fibres were removed from acetic anhydride and washed with running water until acid free and dried in an oven at $80^{\circ} \mathrm{C}$ until a constant weight was obtained.

Table 3 Genetic algorithm parameter setting used for the optimisation

\begin{tabular}{|c|c|c|}
\hline $\mathrm{S} / \mathrm{N}$ & Parameter & Level \\
\hline 1 & Migration Direction & Forward \\
\hline 2 & Population Size & 20 \\
\hline 3 & $\begin{array}{l}\text { Fitness Scaling } \\
\text { Function }\end{array}$ & Rank \\
\hline 4 & Selection Function & Stochastic Uniform \\
\hline 5 & Elite Count & 2 \\
\hline 6 & Crossover Fraction & 0.8 \\
\hline 7 & Mutation Function & $\begin{array}{l}\text { Constrained } \\
\text { Dependent }\end{array}$ \\
\hline $\begin{array}{l}8 \\
9\end{array}$ & $\begin{array}{l}\text { Crossover Function } \\
\text { Hybrid Function }\end{array}$ & $\begin{array}{l}\text { Scattered } \\
\text { None }\end{array}$ \\
\hline
\end{tabular}

\subsection{Water Absorption Test of Bamboo Fibre}

The water absorption test was carried out according to ASTM D3171. One gram each of both modified and unmodified fibres were weighed and immersed in deionised water and placed in a water bath set at $30^{\circ} \mathrm{C}$. Samples were taken out after 1 hour and 24hours respectively, wiped with clean and dry cloth (to remove any water on the surface of the fibres) and weighed to determine the amount of water absorbed. The percentage water absorption was calculated using the formula;

$$
\mathrm{Wa}=\frac{w_{f}-w_{i}}{w_{i}}
$$

Where $W a$ is the percentage water absorption, $w_{f}$ is the Final weight, $w_{i}$ is the initial weight. 


\section{RESULT AND DISCUSSION}

Acetylation parameter settings and the resulting responses are graphically presented in Figure 2 . The responses are mean percentage water absorbed after twenty four hours. Figure 2 show that acetylated fibres absorbed less water than the crude (nonacetylated fibres). The fibres acetylated with the parameter settings R26, with $15 \%$ Acetic Acid, 50minutes soaked time in acetic Acid, 10\% Acetic Anhydride Concentration and 30minutes soaked time in acetic anhydride absorbed the least moisture among all parameter settings.

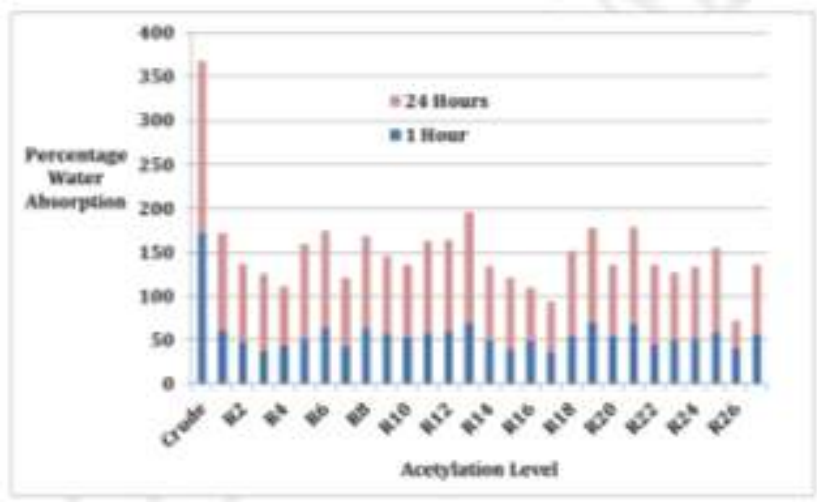

Figure 2: Percentage water absorption of acetylated fibre for different parameter settings

\subsection{Analysis of the S/N Ratio}

Taguchi method minimizes quality characteristic variation due to uncontrollable parameter using signal-to-noise ratio. Percentage water absorption was considered as the quality characteristic with the objective of "the smaller-the-better". The $\mathrm{S} / \mathrm{N}$ ratio used for this type response is given in equation (3).

$$
\text { Smaller the better }=-10 \log \frac{1}{n} \sum y^{2}
$$

Table 4 indicates that the optimal acetylation performance, from Taguchi analysis, for reduced water absorption of bamboo fibres was obtained at $15 \%$ Acetic Acid concentration (level 3), 50minutes soaked time in acetic acid (level 3), 10\% Acetic Anhydride Concentration (level 2) and 30minutes soaked time in Acetic Anhydride. The Ranks indicate that soaked time in acetic acid has the greatest influence followed by acetic anhydride concentration, soaked time in acetic anhydride and then acetic acid concentration.

\subsection{Genetic Algorithm Output}

The regression model generated from Taguchi orthogonal array (equation 2), was used as objective function in Genetic algorithm. Using the same GA parameter setting, five GA trials were conducted to determine the optimum parameter setting and the corresponding response. The result of the trials is shown in Table 5 . Trials 2 to 5 displayed approximately the same optimum parameter settings and response respectively. The optimum parameter settings are $14.99 \%$ (approx 15\%) Acetic Acid, Soaked time in Acetic Acid of 49.99 min (approx. 50minutes), 5\% Acetic Anhydride and soaked time in acetic anhydride of 30 minutes, with response of approximately $44 \%$ water absorption.

Figure 3 (a-d) shows the genetic algorithm output plots for acetylation of Bamboo fibre. Plot (a) displays the best fitness and mean fitness values in each generation.

The best chromosome in each generation is used to produce next generation thereby improving the fitness value. Plot (b) shows the co-ordinates of the variables i.e., acetic acid concentration (1), time soaked in acetic acid (2), acetic anhydride concentration (3), and time soaked in acetic anhydride (4) for the best fitness values. Plot (c) shows the average distance between points in each generation. The amount of mutation influences the average distance between the points.

As the amount of mutation decreases at every stage of generation, the average distance between points is approximately zero at the final generation. Plot (d) displays the number of offspring for each individual in the population.

Table 4 Response table for signal to noise ratios smaller is better

\begin{tabular}{lllll}
\hline \multirow{2}{*}{ Level } & $\begin{array}{l}\text { Acetic Acid Conc. } \\
(\%)\end{array}$ & $\begin{array}{l}\text { Soaked Time in Acetic } \\
\text { Acid (Min) }\end{array}$ & $\begin{array}{l}\text { Acetic Anhydride } \\
\text { Conc. }(\%)\end{array}$ & $\begin{array}{l}\text { Soaked Time in Acetic } \\
\text { Anhydride (Min) }\end{array}$ \\
\hline 1 & -39.55 & -39.92 & -39.15 & $-38.07^{\mathrm{a}}$ \\
2 & -39.03 & -39.29 & $-38.09^{\mathrm{a}}$ & -39.43 \\
3 & $-38.2^{\mathrm{a}}$ & $-37.70^{\mathrm{a}}$ & -39.66 & -39.40 \\
Delta & 1.24 & 2.22 & 1.58 & 1.36 \\
Rank & 4 & 1 & 2 & 3 \\
\hline
\end{tabular}

$\mathrm{a}=$ optimum 
Figure 4 shows the main effect of the process parameters on the percentage water absorption of bamboo fibre. Reduction in water absorption was observed as acetic acid concentration increases. Also, as the time the fibre was soaked in acetic acid increases, the percentage water absorption reduces. Thus, increase in acetic acid concentration and time soaked in acetic acid progressively resulted in reduced moisture absorption. The main effect plot for Acetic Anhydride concentration showed improved performance on percentage moisture absorption as the concentration increased from $5 \%$ to $10 \%$. Further increase in the concentration of acetic anhydride resulted in reduced performance or increased water absorption. For time soaked in acetic anhydride, the lowest level, 30minutes showed the best performance. Increased in time soaked in acetic acid resulted to increased water absorption, that is, decline in performance.

\subsection{Effect of Acetic Acid and Acetic Anhydride on Water Absorption of Bamboo Fibre}

The main effect plot for mean in figure 4 , indicate that percentage water absorption of the fibres decreased with increase in the concentration of Acetic Acid up to the maximum concentration acetic acid used in this research; that is $15 \%$ Acetic Acid. While for Acetic anhydride, the water absorption of the fibre decreased with increased in the concentration up to $10 \%$ concentration after which there was a steady increase in the water absorption. The function of solvent acetic acid is to swell the fibre, since acetic anhydride is not a good swelling agent for cellulose; that is to increase the accessibility of the fibre hydroxyl groups to the acetylating agents, and to dissolve the acetylated product to allow the progress of the reaction[13, 19]. Hence, increasing the amount of solvent acetic acid enhanced the fibre swelling and increased the effect of the acetylation.

Table 5 Genetic algorithm trials

\begin{tabular}{lllllll}
\hline Trial & $\begin{array}{l}\text { Number of } \\
\text { iterations }\end{array}$ & $\begin{array}{l}\mathrm{X}_{1}: \text { Acetic Acid } \\
\text { Concentration }\end{array}$ & $\begin{array}{l}\mathrm{X}_{2}: \text { Time } \\
\text { Soaked in } \\
\text { Acetic Acid }\end{array}$ & $\begin{array}{l}\mathrm{X}_{3} \text { : Acetic } \\
\text { Anhydride } \\
\text { Concentration }\end{array}$ & $\begin{array}{l}\mathrm{X}_{4} \text { : Time Soaked } \\
\text { in Acetic } \\
\text { Anhydride }\end{array}$ & $\begin{array}{l}\text { Y: Percentage } \\
\text { Water } \\
\text { Absorption. }\end{array}$ \\
\hline 1 & 59 & 14.997 & 49.9946 & 5.0099 & 35.1605 & 46.8026 \\
2 & 98 & 14.999 & 49.992 & 5.0023 & 30.0087 & 43.8901 \\
3 & 69 & 14.999 & 49.981 & 5.007 & 30.080 & 43.945 \\
4 & 56 & 14.988 & 49.990 & 5.016 & 30.0009 & 43.9547 \\
5 & 56 & 14.996 & 49.999 & 5 & 30.039 & 43.911 \\
\hline
\end{tabular}

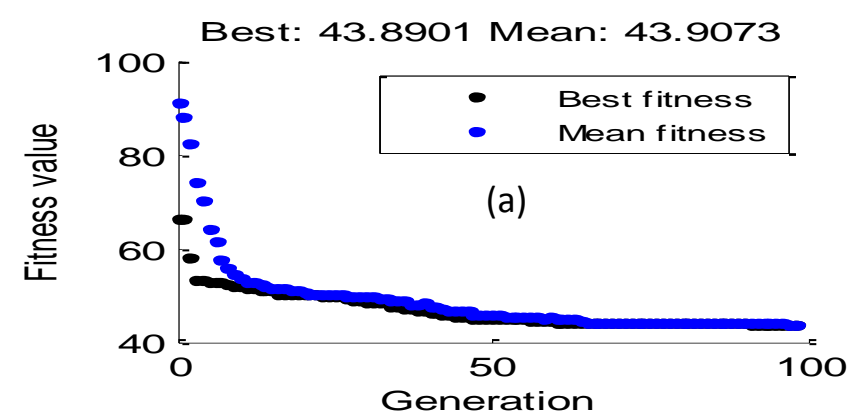

Average Distance Between Individuals

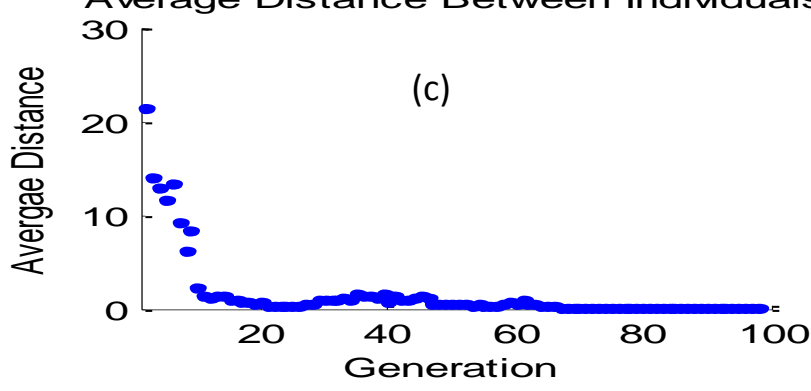

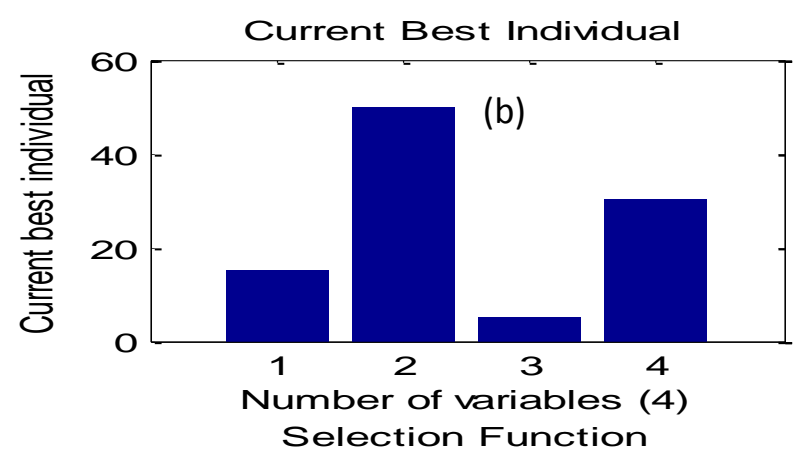

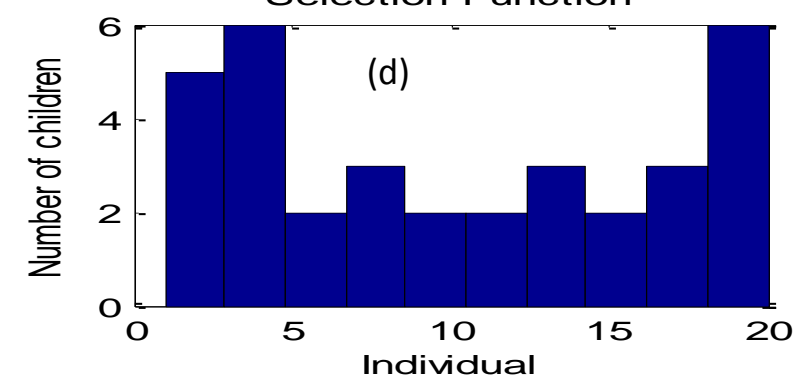

Figure 3 Genetic algorithm output plot 


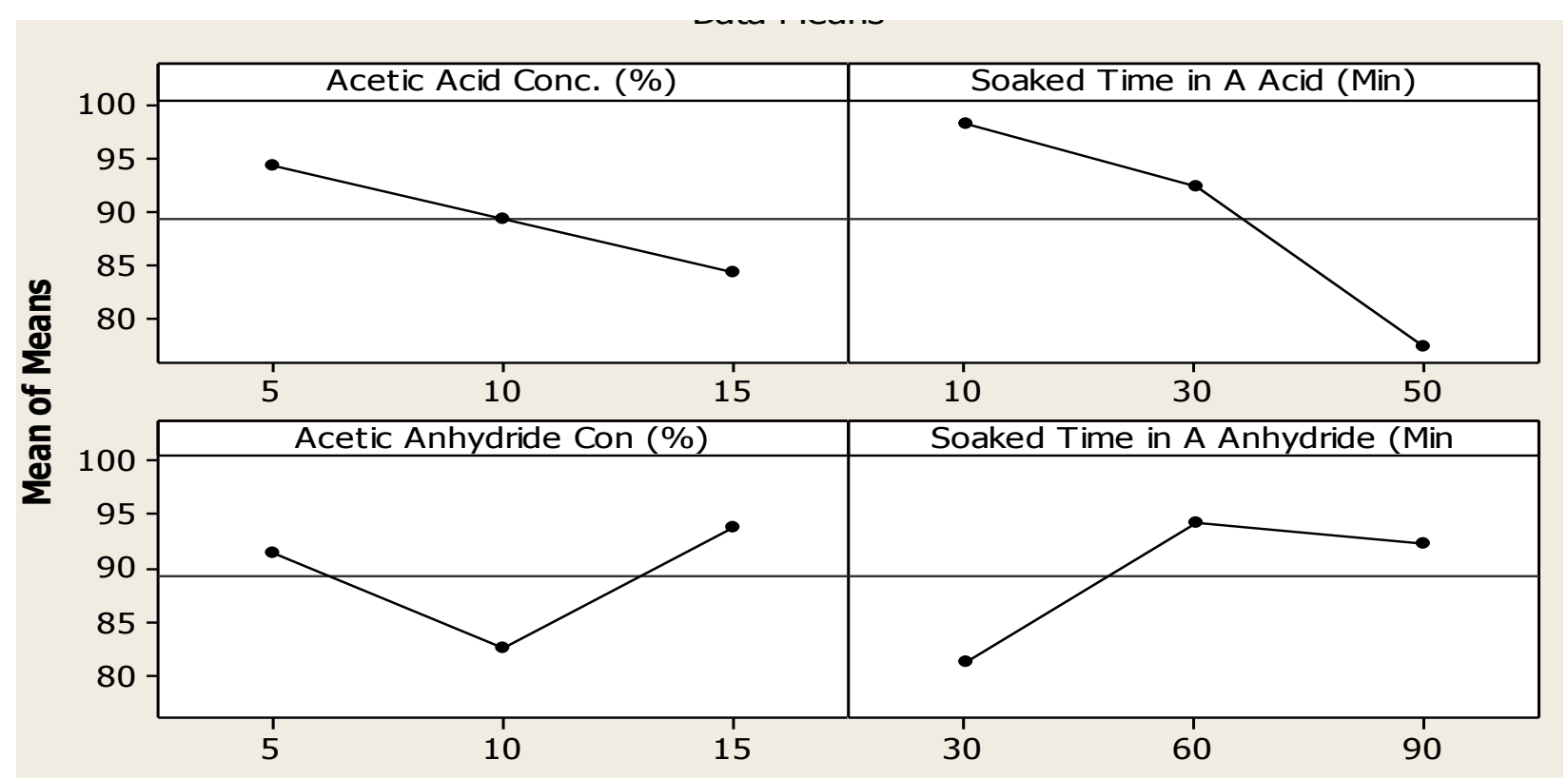

Figure 4 Main effect plots for means

The number of accessible hydroxide group, probably, reached equilibrium at $10 \%$ acetic anhydride concentration. After that point there was a reversal in the performance of the acetylated fibre.

\subsection{Effect of Soaked Time in Acetic Acid and Acetic Anhydride on the Percentage Water Absorption}

Figure 4 shows reduction in percentage water absorption as the soaked time in acetic acid increased. There are easily accessible hydroxyl groups in the cell wall and difficult to access groups [19]. Without soaking the fibre for good enough time in the acetic acid co solvent, which is a swelling agent, only the easily accessible hydroxyl groups will be reached. Soaking fibres for up to 50 minutes in acetic acid allowed the acetyl group from acetic anhydride to reach more hydroxyl groups than soaking for lesser time.

\subsection{Confirmation Experiment}

Table 6 contains the Taguchi Predicted optimal parameter settings, GA predicted optimal parameter settings and the experimental result. It was observed that Taguchi optimal setting corresponds with the optimal parameter setting, R26 of figure 2, obtained from the experiments with percentage water absorption of $45 \%$. Taguchi-predicted optimal setting differs, on optimal acetic anhydride concentration, with GA-predicted optimal parameter setting. Hence, a confirmation experiment was carried out using GA optimal parameter settings, the result indicate 1 percentage difference in the experimental response from the predicted. Thus, Genetic algorithm was effectively implemented to optimise the measured response.

\section{CONCLUSION}

The effect of acetylation on bamboo fibre, using non catalyzed acetylation method at room temperature with acetic anhydride in acetic acid co-solvent, was investigated in this research. Taguchi method was used for the experimental design. Prediction of optimal parameter setting was achieved with Taguchi analysis and Genetic Algorithm.

Table 6 Predicted and experimental data

\begin{tabular}{|c|c|c|c|c|c|}
\hline \multirow[t]{2}{*}{ Method } & \multicolumn{4}{|c|}{ Optimal Parameter Setting } & \multirow{2}{*}{$\begin{array}{l}\text { Percentage } \\
\text { Water } \\
\text { Absorption }\end{array}$} \\
\hline & $\begin{array}{l}\text { Acetic Acid } \\
\text { Concentration } \\
(\%)\end{array}$ & $\begin{array}{l}\text { Time Soaked } \\
\text { in Acetic Acid } \\
\text { (Min.) }\end{array}$ & $\begin{array}{l}\text { Acetic Anhydride } \\
\text { Concentration (\%) }\end{array}$ & $\begin{array}{l}\text { Time Soaked in } \\
\text { Acetic Anhydride } \\
\text { (Min.) }\end{array}$ & \\
\hline Taguchi & 15 & 50 & 10 & 30 & 45 \\
\hline & 15 & 50 & 5 & 30 & 44 \\
\hline Experiment & 15 & 50 & 5 & 30 & 43 \\
\hline
\end{tabular}


Generally, acetylation reduced the percentage water absorption of bamboo fibre; up to $151 \%$ reduction in water absorption was observed. A slight difference was observed in the optimal parameter setting predict by Taguchi analysis and Genetic Algorithm. However, confirmation experiment indicates that both methods are accurate as the difference in response among the three was less than $2 \%$.

\section{REFERENCES}

[1] Maya, J., Rajesh, J., \& Anandjiwala, D. Recent Development in Chemical Modification and Characterisation of Natural Fiber-Reinforced Composite. Polymer Composites, 29, 187-207, 2008.

[2] Rowell, R., Tillman, A., \& Simonson, R. A Simplified Procedure for the Acetylation of Hardwood and Softwood Flakes for Flake Board Production. Wood Chemistry and Technology, 6(3), 427-228. 1986.

[3] Martin, O., \& Paul, W. Modified Wood-Based Panels. In T. Heikon, I. Mark, \& M. Sernek, Wood-Based Panels (pp. 265-278). London: Brunel University Press, 2010.

[4] Maya, J. J., Rajesh, D., Anandjiwala and Sabu T. Hybrid Composites. Journal of Bioenergy, I, 317-329. 2007.

[5] Bakar, A. A., Hassan, A \& Yusof, A. F. M. Effect of Oil Palm Empty Fruit Bunch and Acrylic Impact Modifier on Mechanical Properties and Processability of Unplasticized Poly Vinyl Chloride Composite. Polymer-Plastic Technology and Engineering, 44:1125-1137, 2005.

[6] Nevell, T. P. \& Zeronian, S. H. Wood Fibers. New York: New York WileyPress, 1985.

[7] Kai Huang, M. Z., Guangzhi Zhang, X. J., \& Dan, H. Acetylation Modification of Rice Straw Fiber and Its Thermal Properties. Cellulose Chemistry and Technology, 48 (3-4), 199-207, 2014.

[8] Hassan, M., Onyekwere, O., Yami, A., \& Raji, A. Effects of Chemical Modification on Physical And Mechanical Properties of Rice Husk Stripped Oil Palm Fruit Bunch Fiber Polypropylene Hybrid Composite. IOSR Journal of Mechanical and Civil Engineering (IOSRJMCE), 11 (4), 1-5, 2014.

[9] Papadopoulos, A. N., \& Traboulay, E. Dimensional Stability of OSB made from Acetylated Fir Strands. Holz-Werkstoff, 60, 8487, 2002.
[10] Yakubu, A., Gabriel. A. O., Cheku, M. \& Paul, A. M. Acetylation of Wood Flour from Four Wood Species Grown in Nigeria Using Vinegar and Acetic Anhydride. International Journal of Carbohydrate Chemistry, 20, 1-6, 2013.

[11] Yang, W., \& Tarng, Y. Design optimization of cutting parameters for turning operations based on the Taguchi method. Journal of Material Processing Technology, 84, 122-129, 1998.

[12] Achyut, K., Pandaa, R., \& Singh, K. (2013, July - August). Optimization of Process Parameters by Taguchi Method:Catalytic degradation of polypropylene to liquid fuel. International Journal of Multidisciplinary and Current Research , 50 - 58, 2013.

[13] Kuncoro, D., Andy, P., Robbi, A., Gundhi, A., Herru, S. B., \& Yohanes, F. Effect of Acetylation Treatment and Soaking Time to Bending Strength of Sugar Palm Fiber Composite. AIP Conference Proceedings International Conference on Engineering, Science and Nanotechnology (pp. 1-4). Indonesia: American Institute of Physics. 2016

[14] Mishra, S., K, M. A., Drzal, L. T., Misra, M., Parija, S., Nayak, S., et al. Studies on the Mechanical Performance of Biofibre/glass reinforced polyester hibrid composite. Composite Science and Technology , 63 (10), 1377-1385, 2003.

[15] Janusz, D., \& Patrycja, K. Effect of kenaf fibre modification on morphology and mechanical properties of thermoplastic polyurethane materials. Industrial Crops and Products, 74, 566-576, 2015.

[16] Manikandan, N. K., Thomas, S., \& Groeninckx, G. Thermal and Dynamic Mechanical Analysis of Short Sisal Fibre Reinforced Polystyrene Composite. Composite Science and Technology, 61 (16), 2519-2529, 2001.

[17] Jan, R.. Advanced Genetic Algorithms For Engineering Design Problems. Engineering Mechanics, 17 (5), 407-417, 2010.

[18] Marius-Constantin, O., Popescu, N. E., \& Mastorakis, L. P.. Application of Genetic Algorithm in Electrical Engineering. International Journal of Mathematical Models and Methods in Applied Sciences, 3 (4), 356365, 2009.

[19] John, M., \& Anandjiwala, R.. Recent developments in chemical modification and characterization of natural fiber-reinforced composites. Polymer Composites, 29 (2), 187207, 2008. 